trước điều trị cao nhất là 202946 mUI/ml. Kết quả nghiên cứu của chúng tôi rất khác với các nghiên cứu của các tác giả trong nước: theo Đinh Quốc Hưng [1] nhóm có nồng độ $\beta$ hCG trước điều trị cao nhất là 10.000 đến 50.000 chiếm $35,2 \%$, thấp nhất là nhóm có nồng độ ßhCG trước điều trị nhỏ hơn 1000 chiếm 9,9\%, nông độ $\beta$ hCG trước điều trị thấp nhất là 189 , cao nhất là 123,756. Theo Diêm Thị Thanh Thủy [2] Tỷ lệ nồng độ $\beta$ hCG cao nhất ở nhóm từ 10.000 - $50.000 \mathrm{mÜI} / \mathrm{ml}$ chiếm $47,1 \%$.

Chảy máu phải truyền máu chiếm tỷ lệ cao nhất ở nhóm có nồng độ ßhCG nhỏ hơn 10.000 $\mathrm{mUI} / \mathrm{ml}$ chiếm tỷ lệ là $42,9 \%$, sau đó là nhóm có nồng độ $\beta$ hCG trên $100.000 \mathrm{mUI} / \mathrm{ml}$ chiếm $28,6 \%$.

Trong nghiên cứu cho thấy tất cả các trường hợp tham gia nghiên cứu đều có sự phù hợp giữa chẩn đoán lâm sàng và kết quả giải phẫu bệnh. Kết quả giải phẫu bệnh là gai rau thoái hóa chiếm tỷ lế cao nhất là $69,5 \%$, gai rau thường là $16,9 \%$, chửa $1 / 3$ dưới buồng tử cung có 8 trường hợp là $13,6 \%$.

\section{KẾT LUẬN}

Triệu chứng lâm sàng chửa sẹo mổ lãy thai là ra máu ít một và siêu âm cho kết quả chính xác.

TÀI LIÊUU THAM KHẢO

1. Đinh Quốc Hưng (2011), Nghiên cứu chửa ở sêo mổ lấy thai tại Bệnh viện Phụ Sản Trung Ương, Trường đai hoc Y Y Hà Nôii.

2. Diêm thị Thanhi Thuỷ (2013), Nghiên cưu chửa seo mổ lấy thai tai bênh viện phụ sản Hà Nội, Trường đai hoc Y Hà Nối.

3. Phạm Thị Hải Yến (2014), Đánh giá kết quả điều tri chửa sèo mổ lây thai bằng MTX/ hút thai tai bênh viện Phụ Sản Trung Ương từ tháng 01 năm 2014 đển tháng 9 năm 2014, Đai hoc Y Hà Nôi.

4. Ta Thị Thanh Thủy (2013), Chẩn đoán và điều trị bảo tồn thai vết mổ cũ tai Bệnh viện Hùng Vương. Hội nghị ban chấp hành và nghiên cứu khóa học toàn quốc khóa XVI, p. 23-37.

5. Thân Ngoc Bích (2010), Nghiên cứu chẩn đoán và điều trị chửa ngoài tứ cung tại Bệnh viện Phụ Sản Trung Ương trong 2 năm 1999 và 2009,. Đại hoc Y Hà Nội,

6. Rotas, M.A., S. Haberman, and M. Levgur, Cesarean scar ectopic pregnancies: etiology, diagnosis, and management. Obstet Gynecol, 2006. 107(6): p. 1373-81.

7. Jurkovic, D., et al., First-trimester diagnosis and management of pregnancies implanted into the lower uterine segment Cesarean section scar. Ultrasound Obstet Gynecol, 2003. 21(3): p. 220-7.

\title{
NGHIÊN CỨU VỀ NGUYÊN NHÂN GÂY CHẤN THƯƠNG ĐẦU Ở TRẺ EM
}

Hà Mạnh Tuấn ${ }^{1}$

\section{TÓM TẮT}

Mục tiêu: Mô tả các nguyên nhân gây chấn thương đầu ở trẻ em nhập viện và các đặc điểm có liên quan. Phương pháp nghiên cứu: Nighiên cứu mô tả cắt ngang tiến hành trên các trẻ em dưới 15 tuổi nhập viện vì chấn thương đầu đủ các tiêu chuẩn nghiên cứu từ từ $1 / 7 / 2015$ đến $31 / 6 / 2016$. Các thông tin liên quan đến các biến cần thu thập sẽ được ghi nhận vào phiếu thu thập dữ liệu. Các số liệu sẽ được xử lý bằng phần mềm Epidata 3.1. Kết quả: Có 341 trường hợp đủ tiêu chuẩn nghiên cứu được thu nhân. Tỷ lệ chấn thương đầu ở trẻ nam là $58,7 \%$, và nữ là 41,3\%. Tỷ lệ mắc bệnh theo nhóm tuổi $0-4$ tuổi, 5 9 tuổi và 10 - 15 tuổi lần lượt là $58,4 \%, 27,5 \%$ và $14,1 \%$. Nguyên nhân gây ra chấn thương đâu ở trẻ em là té ngã $(58,7 \%)$, tai nạn giao thông $(41,3 \%)$, và bạo hành $(6,2 \%)$. Nguyên nhân có khác biệt ở các nhóm tuổi khác nhau. Kết luận: Cần quan tâm đến

${ }^{1}$ Đai học Y Dước TP. Hồ Chí Minh

Chịu trách nhiệm chính: Hà Mạnh Tuấn

Email: hamanhtuan@ump.edu.vn

Ngày nhận bài: 15.3.2021

Ngày phản biên khoa hoc: 14.5.2021

Ngày duyệt bài: 21.5.2021 các nguyên nhân gây chân thương đầu ở trẻ em để có cácc biện pháp hiệu quả hướng đến giảm thiểu nguy cơ dẫn đển chấn thương đầu ở trẻ em.

Tư khóa: chấn thương đâu; trẻ em.

\section{SUMMARY}

\section{A STUDY ON CAUSES OF HEAD INJURY IN CHILDREN}

Objectives: Describe the causes of head injury in hospitalized children and characteristics associated with the causes. Methods: A crosssectional descriptive study was conducted on children under 15 years of age hospitalized for head injury who met the study criteria from July 1, 2015 to June 31, 2016. The information related to the variables to be collected will be recorded in the data form. The data will be processed using Epidata 3.1 software. Results: There were 341 cases that met the study criteria. The rate of head injury in boys was $58.7 \%$, and girls was $41.3 \%$. The prevalence by age group $0-4$ years old, 5 - 9 years old and 10 - 15 years old were $58.4 \%$, $27.5 \%$ and $14.1 \%$, respectively. The leading causes of head injury in children were falls $(58.7 \%)$, traffic accidents $(41.3 \%)$, and abuse (6.2\%). The causes were varying in different age groups. Conclusion: It is necessary to pay attention to the causes of head injury in children to 
have effective measures towards reducing the risk of head injury in children.

Keywords; head injury; children.

\section{I. ĐĂT VẤN ĐỀ}

Chấn thương sọ não trẻ em là hậu quả những tác động từ bên ngoài lên vùng đầu của trẻ, có thể do cố ý hay tai nạn và có thể dẫn đến tổn thương da đâu, xương sọ, màng não hay tổn thương nhu mô não. Chấn thương đầu ở trẻ em là một trong những tai nạn khá thường gặp ở trẻ em và có xu hướng gia tắng theo độ tuối của trẻ em. Theo số liệu thống kê của Anh thì xuất độ chấn thương đầu hàng năm ở trẻ khoảng 100 trên 100.000 trẻ em dưới 15 tuổi [1]. Tùy theo mức độ tổn thương, thời điểm phát hiện, các tổn thương đi kèm và cách xử trí các chấn thương đầu ở trẻ em mà hậu quả của chấn thương đầu ở trẻ em có thể thay đổi từ nhe đến nặng thậm chí dẫn đến tử vong. Mức độ tổn thương và hậu quả của chấn thương đầu có liên quan đến nguyên nhân gây ra chấn thương đầu của trẻ em. Nguyên nhân dẫn đến chấn thương đầu ở trẻ em khác với người lớn, ở người lớn chủ yếu liên quan đến tai nạn giao thông hay do tấn công, trong khi đó trẻ em thường do té ngã, tai nạn giao thông, tai nạn trong vui chơi sinh hoat và bạo hành. Việc tìm hiểu các nguyên nhân dấn đến chấn thương đầu ở trẻ em sẽ giúp đưa ra các khuyến cáo về phòng ngừa các tai nạn và sự cố dẫn đến chấn thương đầu ở trẻ em góp phần cải thiện chất lượng chăm sóc trẻ em. Mục tiêu của nghiên cứu này là mô tả các nguyên nhân thường gặp gây ra chấn thương đầu ở trẻ em tại Việt Nam.

\section{II. ĐỐI TƯỢNG VÀ PHƯƠ'NG PHÁP NGHIÊN CỨU \\ Thiết kế nghiên cứu và tiêu chuẩn chọn}

bệnh. Nghiên cứu mô tả cắt ngang đước tiến hànhh tại bệnh viện Nhi Đồng 2 trong thời gian từ 1/7/2015 đến 31/6/2016. Các bênh nhân bị chấn thương đầu nhỏ hơn 15 tuổi nhập vào khoa cấp cứu của bệnh viện được thân nhân đồng ý tham gia nghiên cứu sẽ ghi nhận các thông tin liên quan theo phiếu thu thập nghiên cứu. Các trường hợp có bệnh lý rối loạn đông máu, hay xác định là do bệnh lý mạch máu nội sọ sẽ không đưa vào nghiên cứu. Cõ̃ mẫu là lây trọn tất cả các trường hợp đủ tiêu chuẩn trong thời gian nghiên cứu.

Tiến hành nghiên cứu. Các bệnh nhân nghiên cứu sẽ được ghi nhận các thông tin theo phiếu thu thập dữ liệu. Thông tin nghiên cứu bao gồm các dặc điểm về dân số học, nguyên nhân dẫn đến chấn thương đầu, tình trạng bệnh nhân lúc nhập viện, diễn tiến, xét nghiệp xác định chẩn đoán, can thiệp và kết quả cuổi cùng của bệnh nhân.

Xử lý thống kê. Các biến số định tính được mô tả bằng tần số và tỉ lệ phần trăm; biến số định lượng được mô tả bằng trung bình và độ lệch chuẩn (nểu phân phối chuẩn) hay trung vị và khoảng tứ phân vị (nếu phân phối không chuẩn). Phép kiểm $\mathrm{t}$ dùng để so sánh hai trung bình, phép kiểm Man-Whitney dùng kiểm định các biến phi tham số. Giá trị $p<0,05$ thì được xem là có ý nghĩa thống kê. Các số liệu được xử lý bằng phần mềm Epidata 3.1.

\section{KẾT QUẢ NGHIÊN CỨU}

Có 341 bệnh nhân được đưa vào nghiên cứu trong đó tỷ lệ nam: nữ là 1,41 , tuổi bị chấn thương đâu thường gặp nhất là tuổi từ $0-4$ tuổi, chiếm hơn phân nữa các trường hợp. Nơi cư trú của trẻ bị chấn thương đầu ở các tỉnh chiếm gấp 3 lần so với thành phố Hồ Chí Minh. Chỉ có khoảng 54\% các trường hợp chấn thương đầu trẻ em được chuyển viện bằng xe cấp cứu. Tình trạng lúc nhập viện phần lớn là có điểm Glasgow trên 13 điểm, có $17 \%$ các trường hợp kèm theo đa chấn thương. Đặc biệt là 93,5\% các trường hợp có tổn thương phát hiện trên $\mathrm{CT}$ scan sọ não lúc nhập viện.

\begin{tabular}{|c|c|c|}
\hline Đặc điểm & $\begin{array}{c}\text { Tân số } \\
(\mathrm{n}=341)\end{array}$ & $\begin{array}{l}\text { Tỷ lế } \\
(\%)\end{array}$ \\
\hline Giới: & 200 & 58,7 \\
\hline Nữ & 141 & 41,3 \\
\hline Tuối: $0-4$ tuối & 199 & 58,4 \\
\hline $5-9$ tuối & 94 & 27,5 \\
\hline $10-15$ tuối & 48 & 14,1 \\
\hline \multicolumn{3}{|l|}{ Nơi cư trú } \\
\hline TP. Hồ Chí Minh & 97 & 28,4 \\
\hline Tỉnh khác & 244 & 71,6 \\
\hline Chuyến viện & 184 & 54,0 \\
\hline \multicolumn{3}{|c|}{ Tình trạng lúc nhập viện } \\
\hline Điếm Glasgow lúc nhập viện & & \\
\hline $3-8$ điếm & 35 & 10,3 \\
\hline 9-12 điếm & 53 & 15,5 \\
\hline $13-15$ điếm & 253 & 74,2 \\
\hline Suy hô hấp & 8 & 2,4 \\
\hline Sốc & 3 & 0,9 \\
\hline Dấu hiệu thần kinh định vị & 28 & 8,2 \\
\hline Đa chấn thương & 59 & 17,3 \\
\hline $\begin{array}{l}\text { Có tốn thương trên } \\
\text { CT scan sọ não }\end{array}$ & 319 & 93,5 \\
\hline
\end{tabular}

Bảng 2 cho thấy nguyên nhân và các đăc điểm của chấn thương đâuu trẻ em. Nguyên nhẩn chấn thương đầu do té ngã trong các hoạt động 
của trẻ là thường gặp nhất chiếm hơn phân nữa các nguyên nhân gây chấn thương đầu $(58,7 \%)$, tiếp theo là do tai nạn giao thông $(41,3 \%)$, đặc biệt có khoảng $6,2 \%$ các trường hợp có liển quan đến bạo hành trẻ (hình 1). Nguyên nhân gây chấn thương đầu thay đổi tùy theo nhóm tuổi; bạo hành thường xảy ra chủ yếu ở nhóm tuổi dưới 4 tuổi, té ngã cũng thường gặp nhất lứa tuổi dưới 4 tuổi và từ $5-9$ tuổi, còn tai nạn giao thông rất phổ biến ở nhóm tuổi từ $10-15$ tuổi (hình 2). Phương tiện gây tai nạn giao thông chủ yếu là xe hai bánh có động cơ $(90 \%)$, còn phương tiện trẻ đang sử dụng khi bị tai nạn giao thông là xe hai bánh có động cơ do người thân điều khiển, ngoài ra có $37,9 \%$ các trường hợp trẻ bị tai nạn do đang đi bộ trên đường, và 13,1\% trẻ đi xe đạp. Trong các trường hợp được người thân chở bằng phương tiện xe hai bánh có động cơ chỉ có $14,1 \%$ trẻ đội mũ bảo hiểm. Hoàn cảnh trẻ bị chấn thương đầu phần lớn là đang tham gia giao thông (44,9\%). Có 39\% các trường hợp trẻ bị té ngã do các hoạt động trong nhà, trong đó có té cầu thang $(15 \%$, ) và té do nằm võng không an toàn là $3,5 \%$. Thêm vào đó có $8,2 \%$ các trường hợp chấn thương đầu do các hoạt động trong trường học và 7,9\% các trường hợp chấn thương đầu liên quan đến các hoạt động thể thao.

Bảng 2. Nguyên nhân và đặc điểm gây chấn thương đầu

\begin{tabular}{|c|c|c|}
\hline Đặc điểm & $\begin{array}{c}\text { Tân số } \\
(\mathrm{n}=341)\end{array}$ & $\begin{array}{l}\text { Tỷ lệ } \\
(\%)\end{array}$ \\
\hline \multicolumn{3}{|c|}{ Nguyên nhân gây chấn thương } \\
\hline Té ngã & 167 & 58,7 \\
\hline Tai nạn giao thông & 153 & 41,3 \\
\hline Bị bao hành & 21 & 6,2 \\
\hline \multicolumn{3}{|c|}{$\begin{array}{c}\text { Phương tiện gây ra tai nạn giao thông } \\
(\mathbf{n}=130)\end{array}$} \\
\hline Xe hai bánh có đông cơ & 117 & 90,0 \\
\hline Xe bốn bánh & 13 & 10,0 \\
\hline \multicolumn{3}{|c|}{$\begin{array}{c}\text { Phương tiệ̂n bệnh nhi sử dụng khi bị tai } \\
\text { nạn giao thông }(\mathrm{n}=153)\end{array}$} \\
\hline Xe hai bánh có động cơ & 71 & 46,4 \\
\hline Đi bô & 58 & 37,9 \\
\hline Xe đạp & 20 & 13,1 \\
\hline Xe bốn bánh & 4 & 2,6 \\
\hline \multicolumn{3}{|c|}{ Hoàn cảnh xảy ra tai nạn } \\
\hline Tham gia giao thông & 153 & 44,9 \\
\hline Trong nhà & 133 & 39,0 \\
\hline Trường học & 28 & 8,2 \\
\hline $\begin{array}{l}\text { Hoạt động vui chơi, thế } \\
\text { thao }\end{array}$ & 27 & 7,9 \\
\hline $\begin{array}{c}\text { Đội mũ bảo hiếm } \\
(n=71)\end{array}$ & 10 & 14,1 \\
\hline
\end{tabular}

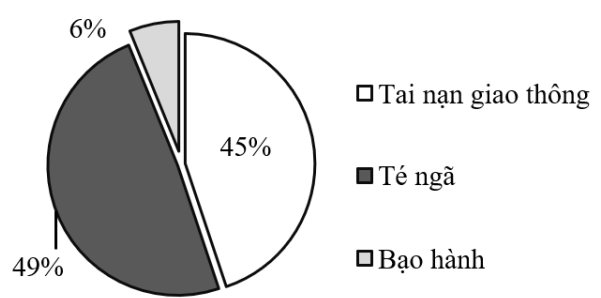

Hình 1. Nguyên nhân gây chấn thương đâu

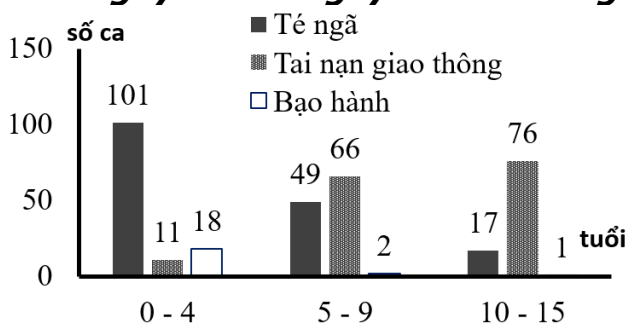

Hình 2. Phân bố nguyên nhân gây chấn thương đâu theo tuôii

\section{BÀN LUÂN}

Nghiên cứu đã ghi nhận được 341 trường hợp chấn thương đâu nhập viện điều trị trong thời gian một năm. Tuổi bị chấn thương đầu trong khảo sát này gặp nhiêu nhất ở lứa tuổi từ $0-4$ tuổi (chiếm 58,4\%), cao hơn gấp đôi so với lứa tuổi từ $5-9$ tuổi và gấp bốn so với lứa tuổi từ 10 - 15 tuổi. Sự phân bố về tuổi bị chấn thương ở trẻ em cũng được ghi nhận trong các nghiên cứu trong nước và nước ngoài về chấn thương đầu ở trẻ em $[1,2,3]$. Lý giải cho việc lứa tuổi thường bị chấn thương đâuu nhỏ hơn 5 tuổi, các tác giả cho rằng là do lứa tuổi này trẻ chưa kiểm soát các hoạt động của mình, ý thức tự bảo vệ chưa có, và tính hiếu động của trẻ em đã làm tăng nguy cơ dẫn đến các chấn thương đâu của trẻ. Ngoài ra cũng như các nghiên cứu trước đây tỷ lệ trẻ nam bi chấn thương đầu thường cao từ $1,4-1,6$ lần so với trẻ em nữ với cùng lý do trẻ trai thường hiếu động hơn trẻ gái $[1,4]$.

Trong nghiên cứu này các trường hợp chấn thương đầu được đưa đến bệnh viện bằng phương tiện xe cứu thương chỉ khoảng hơn phân nữa các trường hợp, mặc dầu hơn hai phần ba các trường hợp bệnh nhân được ghi nhận là sống ngoài thành phố Hồ Chí Minh và $17,3 \%$ các trường hợp có kèm theo các chấn thương khác. Ngoài ra tỷ lệ các trường hợp chấn thương đầu nhập viện trong tình trạng có thay đổi tri giác với điểm số Glasgow $\leq 8$ là $10,3 \%$ cao hơn so với nghiên cứu của Trefan chỉ có $1,9 \%$ các trường hợp chấn thương đầu trẻ em nhập viện với chỉ số Glasgow $\leq 8$ [1], tỷ lệ cần phải can thiệp phẫu thuật cho các bệnh nhân chấn thương đầu 
trong nghiên cứu này là $22,3 \%$ là cao hơn so với nghiên cứu trước đây $[2,4]$. Điều này cho thây việc đánh giá mức độ nghiêm trọng của chấn thương đầu ở trẻ em và hệ thống tiếp nhận và vận chuyển cấp cứu cho bệnh nhân trẻ em bị chấn thương đầu chưa được quan tâm đúng mức nên bệnh nhân nhập viện trong tình trạng khá nặng.

Xét về nguyên nhân gây chấn thương đầu ở trẻ em, nghiên cứu này ghi nhận té ngã là nguyên nhân hàng đầu gây ra chấn thương ở trẻ em, kế đến là tai nạn giao thông và chiếm một tỷ lệ không nhỏ nguyên nhân là bạo hành ở trẻ em. Phát hiện này cũng phù hợp với các nghiên cứu trước đây với 3 nhóm nguyên nhân hàng đầu gây chấn thương đầu ở trẻ em là té ngã (40 $-53 \%)$, tai nạn giao thông $(24-45 \%)$, và một tỷ lệ nhỏ nguyên nhân chấn thương đầu là do bạo hành trẻ em $(0,5-7 \%)[1,2,3,4]$. Tỷ lệ có sự khác biệt trong các nghiên cứu cho từng nhóm nguyển nhân có thể là do cách chọn mẫu, tuy nhiên vẫn tương tự nhau về thứ tự các nguyên nhân thường gặp gây chấn thương đầu ở trẻ em. Tuy nhiên khi xét về phân bố nguyên nhân theo nhóm tuổi thì nghiên cứu này ghi nhận có sự khác biệt theo lứa tuổi. Nguyên nhân té ngã chiếm tỷ lệ cao ở lứa tuổi từ 0 - 4 tuổi, nhưng giảm dần và thấp nhất là ở nhóm tuổi 10 - 15 tuổi. Trong khi đó nguyên nhân do tai nạn giao thông chiếm tỷ lệ tăng dần và cao nhất ở nhóm tuổi từ 10 - 15 tuổi. Đặc biệt bạo hành trẻ em gây chấn thương đầu gặp chủ yếu ở trẻ dưới 4 tuổi mà thường là do ngược đãi hay hội chứng rung lắc trẻ. Sự thay đổi theo lứa tuổi về nguyên nhân gây chấn thương đầu ở trẻ em cũng được ghi nhận trong nghiên cứu trước đây $[1,4,5]$. Điều này có thể lý giải là do trẻ nhỏ ít tham gia giao thông nên chấn thương đầu chủ yếu là do té ngã trong hoạt động hàng ngày của trẻ. Còn trẻ lớn bắt đầu có tham gia giao thông nên tỷ lệ chấn thương đâu do tai nạn giao thông sẽ tăng lên.

Khi phân tích sâu về nguyên nhân dẫn đến chấn thương đầu của trẻ trong nghiên cứu này ghi nhận các trường hợp té ngã liên quan đến các hoạt động đặc biệt trong nhà như té khi leo trèo cầu thang $(15 \%)$ và té khi trẻ nằm trên võng $(3,8 \%)$ chiếm tỷ lệ cao hơn so với té ngã do các hoạt động thông thường khác của trẻ. Đây là điểm mà các bậc phụ huynh cần hết sức lưu ý trong chăm sóc trẻ tại nhà. Cần phải có biện pháp an toàn cho trẻ trong các hoạt động nguy cơ cao như leo trèo câu thang, nằm võ̃ng và thường xuyên giám sát trẻ để tránh các tai nạn đáng tiếc xảy ra. Ngoài ra té ngã dẫn đênn các chấn thương đầu do các hoạt động trong nhà trường, trong các hoạt động thể thao hàng ngày của trẻ cũng được ghi nhận trong nghiên cứu này với tỷ lệ cao. Vì thế cũng cần phải quan tâm đến việc an toàn trong các hoạt động này để phòng tránh tai nạn cho trẻ trong hoạt động hàng ngày.

Nghiên cứu ghi nhận tai nạn giao thông chiếm tỷ lệ cao các nguyên nhân dẫn đến chấn thương đầu ở trẻ em đặc biệt là trẻ từ 5 tuổi trở lên. Phương tiện gây ra tai nạn giao thông trong nghiên cứu này chủ yếu là xe hai bánh có động cơ. Điều này cũng được ghi nhận trong các nghiên cứu của các tác giả Việt Nam[2,3], nhưng lại khác so với các nghiên cứu của các tác giả của các quốc gia mà phương tiện giao thông chủ yếu là xe bốn bánh $[1,4,5,6]$. Phương tiện di chuyển của trẻ khi bị tai nạn giao thông chủ yếu là bằng xe đạp do trẻ tự điều khiển hay xe hai bánh có động cơ do thân nhân điều khiển. Trong các tình huống này tỷ lệ trẻ có đội mũ bảo hiểm chỉ chiếm $14 \%$. Ngoài ra còn có $37,9 \%$ các trường hợp trẻ di bộ cũng bị tai nạn giao thông. Từ ghi nhận này cho thấy việc giáo dục về an toàn giao thông cho trẻ khi tham gia giao thông bằng bất kỳ hình thức nào kể cả đi bộ, và đặc biệt là phải luôn đội mũ bảo hiểm khi sử dụng phương tiện xe gắn máy và kể cả xe đạp để phòng tránh các tai nạn giao thông trong đó có chấn thương đầu.

Ngoài ra trong khảo sát này cũng ghi nhận một tỷ lệ rất đáng quan tâm các trường hợp chấn thương đầu do bạo hành ở trẻ em, mà trong đó có các trường hợp do rung lắc trẻ trong quá trình chăm sóc dẫn đến chấn thương đâu. Phát hiên này là một cảnh báo về việc cần quan tâm đến ngăn chặn và chấm dứt bạo hành trẻ em và các hoạt động rung lắc trẻ để đỗ dành khi trẻ khóc để làm giảm nguy cơ dẫn đến chấn thương đầu ở trẻ em.

\section{KẾT LUẬN}

Chấn thương đầu trẻ em là tai nạn đối với trẻ với xuất độ ngày càng tăng phải cần được quan tâm đúng mức hơn. Các nguyên nhân thường gây chấn thương đầu ở trẻ em là té ngã, tai nạn giao thông và bạo hành có thay đổi theo nhóm tuổi trẻ. Cần phải tăng cường giáo dục và nâng cao nhận thức cho thân nhân, các người có liên quan đến trẻ và bản thân các trẻ em về việc thực hiện các biện pháp an toàn trong các hoạt động nểu trên nhằm giúp giảm nguy cơ dẫn đển chấn thương đầu của trẻ. 


\section{TÀI LIÊU THAM KHẢO}

1. Trefan, R. Houston, G. Pearson, R. Edwards, et al (2016) "Epidemiology of children with head injury: a national overview", Arch Dis Child, 101 (6), pp. 527-32.

2. Hố Trí Hùng (2009), Nghiên cứu một số đặc điểm của chấn thương so não trẻ em, Luân án Chuyên khoa cấp II, Đại học Y Dược Thành phố Hồ Chí Minh.

3. Nguyễn Huy Luân (2010), Đánh giá áp dụng phân loại của Schutzman trong chỉ định chụp CT scan sọ não ở trẻ bị chấn thương đâu có điểm hôn mê của Glasgow từ 13-15 điểm, Luận án tiến sĩ y hoc, Đai hoc Y Dược Thành phố Hồ Ċí Minh.

4. K. S. Quayle, E. C. Powell, P. Mahajan, et al (2014), "Epidemiology of blunt head trauma in children in U.S. emergency departments", N Engl J Med, 371 (20), pp. 1945-7.

5. S. L. Chong, S. Y. Chew, J. X. Feng, et al (2016) "A prospective surveillance of paediatric head injuries in Singapore: a dual-centre study", BMJ Open, 6 (2), e010618.

6. M. O. Nnadi, O. B. Bankole, B. G. Fente (2014) "Epidemiology and treatment outcome of head injury in children: A prospective study", J Pediatr Neurosci, 9 (3), pp. 237-41.

\section{MộT Số ĐĂC ĐIỂM DİCH TỄ LÂM SÀNG BỆNH NHÂN CHẤN THƯƠNG SO NÃO ĐIỀU TRI TẠI BỆNH VIỆN ĐA KHOA TİNH THÁI BÌNH: NHÂN 534 TRƯờNG HỢP}

\section{TÓM TẮT}

Mục tiêu: Nhận xét một số đăc điểm dich tễ lâm sàng, tổn thương trên cắt lớp vi tính 534 bênh nhân chấn thương so não điều trị tại khoa Phẩu thuât Thần kinh-Cột sông Bệnh viên Đa khoa tỉnh Thái Bình. Phương pháp: Mô tả cắt ngang 534 bênh nhân chấn thương sọ não điều trị tại Bệnh viện Đa khoa tỉnh Thái Bình từ tháng 2 đến tháng 9 năm 2020. Kết quả: 534 bệh nhân gồm 371 nam $(69,5 \%), 163$ nữ $(30,5 \%)$ Đồ tuổi trung bình 54,5 $\pm 21,9$; nhỏ tuổi nhất: 2 tuôi, lớn tuổi nhất: 96 tuổi. Nhóm tuổi lao động (57,3\%), người cao tuổi (30,2\%). Nguyên nhân tai nạn giao thông chiếm đa số $(60,5 \%)$. Tî lệ chấn thương sọ não nhe theo GCS: 501 bệnh nhân $(93,8 \%)$; trung bình: 23 bênh nhân (4,3\%); nặng: 10 bệnh nhân (1,9\%). Cắt lớp vi tính: Máu tư dưới màng cứng $(28,7 \%)$; chảy máu màng mềm $(27,3 \%)$; võ xương sọ $(12,7 \%)$; có 2 tổn thương phối hợ $(8,8 \%) ; 3$ tổn thương $(3,0 \%)$. Thái độ xử trí: Điều trị nội khoa 473 bệnh nhân $(88,6 \%)$; phẫu thuật 51 bênh nhân $(9,5 \%)$. Kết quả ra viện: 512 bệnh nhân $(95,9 \%)$ ổn định; sống thực vật 5 bệnh nhân $(0,9 \%)$; Tử vong 1 bệnh nhẩn $(0,2 \%)$. Kết luận: Nguyên nhân chấn thương sọ não do tai nạn giao thông vẫn cao nhất; thường gặp ở nam giới và độ tuổi lao động. Tỉ lệ điều trị nội khoa chiếm đa số, phẫu thuật chỉ chiếm $(9,5 \%)$.

Tư khóa: Chấn thương so não; dich tễ học lâm sàng chấn thương sọ não.

SUMMARY

\footnotetext{
*Trường Đại học Y Dược Thái Binh Chiu trách nhiếm chính: Vũ Minh Hải Email: vuminhhai777@gmail.com Ngày nhận bài: 16.3 .2021 Ngày phản biên khoa hoc: 5.5.2021 Ngày duyệt bài: 14.5.2021
}

Vũ Minh Hải*, Đoàn Văn Ánh*

SOME CLINICAL EPIDEMIOLOGICAL
CHARACTERISTICS OF CRANIOCEREBRAL
INJURY PATIENTS TREATED AT THAI BINH
GENERAL HOSPITAL

Objectives: To assess some clinical epidemiological characteristics, lesions on CT scan in 534 craniocerebral injury patients treated at the Neurological \&Spinal Surgery of Thai Binh General Hospital. Methods: Cross-sectional descriptive study carried out in 534 craniocerebral injury patients treated at Thai Binh Provincial General Hospital from February to September 2020. Results: 534 patients included 371 males (69.5\%), 163 females (30.5\%), median age 54.5, youngest: 2 years old, oldest: 96 years old. Working age group (57.3\%), elderly people $(30.2 \%)$. The most common cause was traffic accidents $(60.5 \%)$. Rate of minor craniocerebral injuries according to GCS: 501 patients (93.8\%); moderate: 23 patients (4.3\%); severe: 10 patients (1.9\%). CT scan: Subdural hematoma (28.7\%); Subarachnoid hemorrhage $(27.3 \%)$; skull fracture $(12.7 \%) ; 2$ patients having associated injuries $(8.8 \%)$; 3 lesions $(3.0 \%)$. Management: conservative treatment for 473 patients $(88.6 \%)$; surgery for 51 patients $(9.5 \%)$. Discharge results: 512 patients $(95.9 \%)$ were recuperated; vegetative state: 5 patients $(0.9 \%)$; One died $(0.2 \%)$. Conclusion: traffic accidents were the major cause of traumatic brain injuries; common in makes and working age group. The rate of conservative treatment was the most, surgery only accounted for $(9.5 \%)$, mortality in the study was $(0.2 \%)$.

Keywords: Traumatic brain, craniocerebral injury; Clinical epidemiological of traumatic brain injury.

\section{I. ĐĂT VẤN ĐÊ}

Chấn thương sọ não là một cấp cứu ngoại khoa thường gặp, và là nguyên nhân gây gây tử 